\title{
A study of thermally-induced sex reversal in casque-headed lizards
}

Gabriel Suárez-Varón ${ }^{1}$, Eva Mendoza-Cruz², Armando Acosta ${ }^{3}$, Maricela Villagrán-Santa Cruz², Diego Cortez (ORCID: 0000-0003-0654-6349) ${ }^{3 *}$, Oswaldo Hernández-Gallegos ${ }^{1}$

8 1) Laboratorio de Herpetología, Facultad de Ciencias, Universidad Autónoma del Estado de México, Instituto Literario \# 100 Centro, Toluca, Estado de México, C.P. 50000, México.

11 de Ciencias, Universidad Nacional Autónoma de México, C. P. 04510, Ciudad de México, México.

12 3) Centro de Ciencias Genómicas, UNAM, C.P. 62210, Cuernavaca, México.

*Corresponding author: Diego Cortez (dcortez@ccg.unam.mx)

Emails: biogabrielsv@gmail.com, EvaMendoza@ciencias.unam.mx, agalariept84@gmail.com,

21 maricelavisa@yahoo.com.mx, dcortez@ccg.unam.mx, ohg070606@gmail.com.

31 Keywords: sex chromosomes; sex reversal; temperature-dependent sex determination; casque32 headed lizards; development of gonads; embryonic development. 


\section{ABSTRACT}

34 Non-avian reptiles, unlike mammals and birds, have undergone numerous sex determination 35 turnovers. For example, casque-headed lizards replaced the ancestral XY system shared across 36 pleurodonts with a new pair of $X Y$ chromosomes. However, the evolutionary forces that triggered 37 this transition have remained unclear. An interesting evolutionary hypothesis suggests that species 38 with intermediate states, with sex chromosomes but also thermal-induced sex reversal at specific 39 incubation temperatures, could be more susceptible to sex determination turnovers. We contrasted 40 genotypic data (presence/absence of the $Y$ chromosome) against the histology of gonads of embryos 41 from stages $35-37$ incubated at various temperatures, including typical male-producing $\left(26^{\circ} \mathrm{C}\right)$ and 42 female-producing $\left(32^{\circ} \mathrm{C}\right)$ temperatures. We observed perfect concordance between genotype and 43 phenotype at all temperatures. However, analysis of transcriptomic data from embryos incubated 44 at $26^{\circ} \mathrm{C}$ and $32^{\circ} \mathrm{C}$ identified transcript variants of the chromatin modifiers JARID2 and KDM6B that 45 have been linked to temperature-dependent sex determination in other reptiles. Besides, our work 46 reports for the first time to our knowledge the histology of gonads, including morphological 47 changes, from stages 35-37 of development in the Corytophanidae family. We also observed that all 48 embryos developed hemipenes, suggesting sex-linked developmental heterochrony.Our work 49 tested the validity of a mixed sex determination system in the Corytophanidae family. We showed 50 that $X Y$ chromosomes are dominant, however, our work supports the hypothesis of a conserved 51 transcriptional response to incubation temperatures across non-avian reptiles that could be the 52 reminiscence of an ancestral sex determination system.

\section{INTRODUCTION}

56 Although squamate reptiles are the most species-rich group among non-avian reptiles ( $96.3 \%$ of the 57 diversity [1]) their sex-determination mechanisms remain poorly understood. In squamate reptiles, 58 sex determination occurs by two general strategies: genotypic sex determination (GSD, the norm 59 for Squamata) and temperature-dependent sex determination (TSD). In the first strategy, specific 60 sex chromosomes control the development of the gonads, whereas in the second strategy, external 61 cues, typically ambient temperature, regulate the sexual differentiation of ovaries and testis [2]. In 62 many TSD species, $\sim 26^{\circ} \mathrm{C}$ produces $100 \%$ of males (i.e., male-producing temperature), whereas $63 \sim 32^{\circ} \mathrm{C}$ produces $100 \%$ of females (i.e., female-producing temperature). For many years it was 64 assumed that GSD and TSD were mutually exclusive; however, as more non-avian reptiles have been 
studied in detail, we now understand that GSD and TSD represent the endpoints of a continuum [3, 4] with some lizards showing temperature-induced sex reversal where ambient temperature can alter the genetic pathways of gonad differentiation [5]. Several squamate reptiles such as Niveoscincus ocellatus [6], Eulamprus heatwolei [7, 8], Pogona vitticeps [9, 10], and Bassiana duperreyi $[4,11]$ show intermediate states where the sex of the offspring is controlled by sex chromosomes under medium incubation temperatures but sex-linked genes can be overridden by alternative signaling cascades at elevated (P. vitticeps [10]) or lowered incubation temperatures ( $B$. duperreyi [12]).

Mammals and birds have stable sex chromosomes. Non-avian reptiles, however, have undergone numerous sex determination turnovers with lineages shifting from TSD to GSD and vice versa [13]. A general explanation of why sex determination turnovers are more common in reptiles is lacking. Analyses of ancestral states indicated that the last common ancestor of all reptiles had TSD [14, 15] and, subsequently, GSD systems originated in some lineages $[14,15]$. It is possible, therefore, that the TSD systems we observe nowadays in turtles, crocodiles, and some lizards derive from the ancestral TSD system $[8,16]$.

Non-avian reptiles are thought to have evolved temperature-dependent sex determination because their embryos develop in a close relationship with the environment [17]. An interesting evolutionary hypothesis suggests that species with intermediate states showing sex chromosomes and thermalinduced sex reversal may be more susceptible to sex determination turnovers [18] because the ancestral TSD system is still present but has been overridden by, for example, sex chromosomes [8]. This hypothesis is supported by observations in $P$. vitticeps where TSD becomes the dominant sex determination system when the ZW chromosomes are lost [9]. Moreover, three phylogenetically distant reptiles, a turtle (Trachemys scripta), a crocodile (Alligator mississippiensis), and an acrodont lizard ( $P$. vitticeps), showed the same temperature-dependent spliced isoforms of two members of the Jumonji family of chromatin modifiers, KDM6B and JARID2 [16]; KDM6B plays an important role in temperature-dependent sex determination signaling cascade because its knockdown results in a male-to-female sex reversal at male-producing temperatures in T. scripta [19]. JARID2 has been proposed to play an important role in the temperature-dependent sex determination pathway in non-avian reptiles [20]. 
97 Pleurodonts, including iguanas, spiny lizards, and Anolis have a common XY system [21, 22]. In Anolis

98 carolinensis, researchers characterized a highly degenerated $Y$ chromosome and a perfect dosage

99 compensation mechanism that over-expresses the $X$ chromosome in males [23]. In the pleurodont

100 clade, however, casque-headed lizards (Corytophanidae family) replaced the ancestral XY system

101 with a new pair of $X Y$ chromosomes [24, 25]. Moreover, initial observations performed in our

102 laboratory with clutches of the Brown Basilisk (Basiliscus vittatus), a casque-headed lizard, indicated

103 that female-biased offspring may occur at medium-high incubation temperatures $\left(\sim 29^{\circ} \mathrm{C}\right)$. In this

104 study, we explored the proximate mechanisms of sex determination in a squamate reptile, tested

105 whether Basiliscus vittatus, a casque-headed lizard, showed temperature-dependent sex reversal.

106 Moreover, we also explored the possibility that $B$. vittatus exhibited genetic signatures of an

107 ancestral temperature-dependent sex determination system.

109 MATERIALS AND METHODS

110 Animal collection

11122 gravid females of $B$. vittatus were collected from a population that inhabits the tropical rainforest 112 habitat at the community of "La Selva del Marinero" in Veracruz, México $\left(18^{\circ} 26^{\prime} 36.3^{\prime \prime} \mathrm{N}\right.$, $11394^{\circ} 37^{\prime} 81.9^{\prime \prime W}$, ca. 170 m a.s.I.; SEMARNAT Scientific Collector Permit 08-043). We sampled from

114 April to July of 2018 and females were captured manually and with help of a noose. To evaluate the 115 reproductive condition, both visual assessment and an abdominal palpation were performed 116 (females with eggs showed multiple contours in the abdomen area). Gravid females showed the 117 following morphometric data (mean \pm standard error): $\mathrm{LHC}=128.1 \pm 1.4 \mathrm{~mm}$, and weight $59.6 \pm 2.3$

120 Laboratory conditions

121 Gravid females were placed inside terrariums (100 cm width $\times 50 \mathrm{~cm}$ depth $\times 50 \mathrm{~cm}$ height) until the 122 termination of oviposition. One female per terrarium at a thermal gradient between $20-40^{\circ} \mathrm{C}, \mathrm{a}$ 123 photoperiod of $12 / 12 \mathrm{~h}$ (photofase/scotophase), constant humidity, live insects as food, and water 124 ad libitum. The terrariums were monitored daily. 82 eggs were collected and randomly assigned to 125 three incubation temperatures, $26^{\circ} \mathrm{C}, 29^{\circ} \mathrm{C}$, and $32^{\circ} \mathrm{C}$. Eggs were incubated at the three 126 temperatures in three Percival L-30 incubators until they reached relatively late developmental 127 stages (35-37 according to the development table established by Dufaure and Hubert [26]). We 128 chose these stages because gonads should be fully determined. 48 eggs $\left(12,18,18\right.$ for $26^{\circ} \mathrm{C}, 29^{\circ} \mathrm{C}$, 
129 and $32^{\circ} \mathrm{C}$, respectively) reached stages 35-37. The posterior part of the embryos was dissected and

130 fixed using Bouin solution for 30 minutes, washed with water for 30 minutes, and stored in $10 \%$

131 formaldehyde for further histological analysis. The rest of the embryo's body was stored in

132 DNA/RNA shield buffer by Zymo Research (Cat. No. R1200-125) for further genetic analysis.

133 Microscopy analysis

134 Conventional histological techniques were performed on each sample: dehydration via graded 135 ethanol, clearing tissues in xylene, and embedding tissues in Paraplast (Sigma-Aldrich, Cat. No. 136 145686-99-3). Histological sections were made at five microns and stained with Ehrlich-Eosin 137 Hematoxylin (Sigma-Aldrich, Cat. No. 17372-87-1) to facilitate the description of the structures. 138 Samples were then viewed and imaged via a compound microscope including a digital camera.

DNA extraction and Y-specific PCR analysis

141 We collected $25 \mathrm{mg}$ of tissue and we purified DNA using the QIAamp Fast DNA Tissue Kit from 142 QIAGEN (Cat. No. 51404). We verified the integrity of the DNA using 1\% agarose gels. All DNA 143 samples were tested for integrity (260/280 and 260/230 ratios >1.8), using a NanoDrop 2000 144 spectrophotometer (Thermo Scientific), and quantified in a Qubit 4 fluorometer (Thermo Scientific, 145 MA, USA) with the Qubit dsDNA BR Assay kit from the same supplier. We confirmed the presence 146 or absence of a Y chromosome in the samples using Y-specific primers designed previously [24]: 147 CAMSAP1Y, forward: AGT CTC AGT CTG CAC CAG TGA AAG, reverse: TGA TTT CTG AGC CCA GGC AGT 148 T. GOLGA2Y, forward: AGG CTG TCA GTC TCA CTC AGT AAG, reverse: CCC CAT ATT CCC AGG TTC TGT 149 CA. We verified that PCR reactions worked using primers against COL1A1 (autosomal/control) 150 forward: TTT CGT GCA GGG TGG GTT CTT T, reverse: TCT GAA CTG GTG CAG CTT CAC A. We used 151 the Phusion Flash High Fidelity from Thermo Fisher Scientific (Cat. No. F548L) with the following 152 program: first $98^{\circ} \mathrm{C}-10 \mathrm{~s}$, then 30 cycles of $98^{\circ} \mathrm{C}-2 \mathrm{~s}, 66^{\circ} \mathrm{C}-5 \mathrm{~s}$ and $72^{\circ} \mathrm{C}-10 \mathrm{~s}$, with a final elongation 153 step at $72^{\circ} \mathrm{C}-30 \mathrm{~s}$. We confirmed the size of the PCR products and the presence of single amplicons 154 in a $1 \%$ agarose gel.

156 RNA extraction and RNA-seq analysis

157 We generated strand-specific RNA-seq libraries (using the Illumina TruSeq Stranded mRNA Library 158 protocol) for a total of six samples obtained from whole embryos incubated at $26^{\circ} \mathrm{C}$ (four samples; 159 three females and one male) and $32^{\circ} \mathrm{C}$ (two samples; two females). Embryos were sexed using the 
160 above-mentioned Y-specific primers. Each library was sequenced on Illumina HiSeq 2500 platforms

161 at the Macrogene facility in Korea (100 nucleotides, paired-end). We generated 31,910,378 million

162 reads on average $( \pm 3,753,014$ million reads). We reconstructed a full transcriptome using Trinity

163 (v2.0.2, default k-mer of $25 \mathrm{bp}$ ) [27]. Then, RNA-seq reads from $26^{\circ} \mathrm{C}$ and $32^{\circ} \mathrm{C}$ samples were mapped

164 to the reconstructed transcriptome using Kallisto (100 bootstraps) [28]. We obtained the estimated

165 counts per transcript and we used the EdgeR package [29] to perform differential expression

166 analyses of transcripts between incubation temperatures $\left(26^{\circ} \mathrm{C}\right.$ versus $32^{\circ} \mathrm{C}$, and vice versa). We

167 used the edgeR and splines R libraries, TMM (Trimmed Mean of M-values) normalization, FDR (False

168 Discovery Rate) set at 0.0001 given the limited number of replicates at $32^{\circ} \mathrm{C}$, from which non-

169 degraded RNA was difficult to obtain. We downloaded from the Ensembl database

170 (https://www.ensembl.org/; v.92) the cDNAs and IncRNAs from A. carolinensis and we used BLASTn

$171[30]$ to assign gene identities to the differentially expressed transcripts. When various transcripts

172 for the same gene were differentially expressed, count estimates were added to obtain single values

173 per gene. Enrichment analyses were carried out using Webgestalt (http://www.webgestalt.org/),

174 specifying over-representation analysis, the genontology database, and the Biological Process

175 category. RNA-seq data have been deposited to the NCBI-SRA database under BioProject

176 PRJNA766022.

178 RESULTS

179 Histological analysis showed that ovaries and testes were well-differentiated in stages 35-37 of 180 development

181 To evaluate the effect of temperature on the embryo's sex, first, we established the developmental

182 stages where gonads were well-differentiated. We observed clear testis-specific and ovary-specific

183 structures in stages 35-37 of embryonic development. During stage 35, the female ovary showed an

184 oval morphology (Fig. 1a). The cortex and the medullary zone were well-differentiated. The cortex

185 is structured by epithelial and germ cells, and the presence of some oogonia were visible. The

186 testicle in stage 35 showed testicular cords in the medullary region together with epithelial cells,

187 the future Sertoli cells (Fig. 1b). Some of these cords presented spermatogonia in the lumen, around

188 the medullary area. In stage 36 , the ovary size increased, the cortical zone became thicker showing

$1892-3$ layers of germ cells, closely related to somatic cells or future follicular cells in their thickest part,

190 delimited by a basal lamina of connective tissue, in addition to a greater number of oogonia than in

191 the previous stage (Fig. 1c). Testicles in stage 36 were more elongated, testicular cords increased in 
192 density in the medullary region (Fig. 1d), and spermatogonia were common inside the testicular

193 cords. Finally, in stage 37, connective tissue fibers in the ovaries delimited the cortical zone and the

194 medullary region (Fig. 1e). In the cortical region, the proliferation of oogonia covered the entire

195 region. As for the testicles, in stage 37, the shape was elongated and curved and the entire testicle

196 is made up of testicular cords, which were located more closely to the central area of the spinal

197 cord. Large spermatogonia became abundant inside the testicular cords, while Sertoli cells are

198 peripheral to the testicular cords (Fig. 1f).

Fig. 1. Ovaries and testes at stages 35-37 of development in B. vittatus embryos. a) histology of the ovary in stage 35. b) histology of the testis in stage 35 . c) histology of the ovary in stage 36 . d) histology of the testis in stage 36. e) histology of the ovary in stage 37. f) histology of the testis in

\section{No effect of incubation temperatures on the sex of $B$. vittatus embryos}

208 Next, we performed experiments to evaluate whether the sex of the embryos was affected by 209 different incubation temperatures, including typical male-producing $\left(26^{\circ} \mathrm{C}\right)$ and female-producing $210\left(32^{\circ} \mathrm{C}\right)$ temperatures. To do so, we contrasted genotypic data (i.e., presence/absence of the $Y$ 211 chromosome) against the histology of the gonads from stages 35-37 (i.e., presence of testicular or 212 ovarian structures) at three incubation temperatures $\left(26^{\circ} \mathrm{C}, 29^{\circ} \mathrm{C}\right.$, and $\left.32^{\circ} \mathrm{C}\right)$. If $\mathrm{B}$. vittatus presented 213 temperature-dependent sex reversal, specific genotypes would not necessarily develop the 214 expected gonads. For example, in a male-to-female sex reversal, individuals with a Y chromosome 215 would develop ovaries.

217 We analyzed a total of 48 embryos. At $26^{\circ} \mathrm{C}$ we observed eight embryos with a $\mathrm{Y}$ chromosome and 218 four embryos without a $Y$ chromosome (Fig. 2). At $29^{\circ} \mathrm{C}$ we observed 11 embryos with a $Y$ 219 chromosome and seven embryos without a $Y$ chromosome (Fig. 2). At $32^{\circ} \mathrm{C}$ we observed nine 220 embryos with a $Y$ chromosome and nine embryos without a $Y$ chromosome (Fig. 2). We detected 221 the same frequency of males and females at the three temperatures ( $X^{2}$ test, $\left.P>0.05\right)$. Moreover, 222 after contrasting the genotype of the embryos against their gonads, we found that embryos with a 223 Y chromosome developed testes in all instances. Similarly, embryos without a Y chromosome 224 always developed ovaries (Fig. 2). 
227 Fig. 2. Number of embryos according to the incubation temperature, genotype, and histology.

228 Histogram showing the number of $B$. vittatus embryos with a $Y$ chromosome that developed testes 229 (Ychr+ts; no sex reversal), the number of embryos lacking a $Y$ chromosome that developed ovaries 230 (noY+ov; no sex reversal), the number of embryos with a $Y$ chromosome that developed ovaries 231 (Ychr+ov; male-to-female sex reversal), and the number of embryos without a $Y$ chromosome that 232 developed testes (noY+ts; female-to-male sex reversal).

\section{Differential expression analysis of transcriptomic data}

236 We performed a differential expression analysis of RNA-seq data from embryos incubated at $26^{\circ} \mathrm{C}$ 237 versus embryos incubated at $32^{\circ} \mathrm{C}$. We found 272 genes that were over-expressed at $26^{\circ} \mathrm{C}$ and 136 238 genes that were over-expressed at $32^{\circ} \mathrm{C}$ (S1 Table). Enrichment analysis of GO terms showed that 239 differentially expressed genes were associated, as expected, with biological processes that are 240 common during embryonic development. Interestingly, however, genes over-expressed at $26^{\circ} \mathrm{C}$ 241 were more frequently associated with neuron development (Table 1), whereas genes over242 expressed at $32^{\circ} \mathrm{C}$ were mostly associated with muscle development (Table 2).

Table 1. GO terms enrichment of genes over-expressed at $26^{\circ} \mathrm{C}$

\begin{tabular}{|c|c|c|c|c|c|c|}
\hline Gene Set & Description & Size & Expect & Ratio & P Value & FDR \\
\hline GO:0048666 & neuron development & 1068 & 15.382 & 3.251 & 7.57E-14 & $6.88 \mathrm{E}-10$ \\
\hline GO:0010975 & regulation of neuron projection development & 475 & 6.8411 & 4.678 & $3.48 \mathrm{E}-13$ & $1.58 \mathrm{E}-09$ \\
\hline GO:0030030 & cell projection organization & 1522 & 21.92 & 2.692 & $9.84 \mathrm{E}-13$ & $2.98 \mathrm{E}-09$ \\
\hline GO:0120036 & plasma membrane bounded cell projection organization & 1488 & 21.431 & 2.66 & $4.33 \mathrm{E}-12$ & 9.83E-09 \\
\hline GO:0120035 & $\begin{array}{l}\text { regulation of plasma membrane bounded cell projection } \\
\text { organization }\end{array}$ & 665 & 9.5775 & 3.759 & $6.61 \mathrm{E}-12$ & $1.20 \mathrm{E}-08$ \\
\hline GO:0022604 & regulation of cell morphogenesis & 473 & 6.8123 & 4.404 & $9.31 \mathrm{E}-12$ & $1.26 \mathrm{E}-08$ \\
\hline GO:0031344 & regulation of cell projection organization & 674 & 9.7072 & 3.709 & $9.72 \mathrm{E}-12$ & $1.26 \mathrm{E}-08$ \\
\hline GO:0031175 & neuron projection development & 940 & 13.538 & 3.176 & $1.23 \mathrm{E}-11$ & $1.39 \mathrm{E}-08$ \\
\hline GO:0030182 & neuron differentiation & 1313 & 18.91 & 2.697 & 4.67E-11 & $4.72 \mathrm{E}-08$ \\
\hline GO:0000902 & cell morphogenesis & 982 & 14.143 & 2.97 & $1.81 \mathrm{E}-10$ & $1.55 \mathrm{E}-07$ \\
\hline
\end{tabular}

Table 2. GO terms enrichment of genes over-expressed at $32^{\circ} \mathrm{C}$

\begin{tabular}{|l|l|r|r|r|r|r|} 
Gene Set & Description & \multicolumn{2}{c}{ Size Expect } & \multicolumn{2}{c|}{ Ratio P Value } & FDR \\
\hline GO:0003012 & muscle system process & 423 & 3.1984 & 8.754 & 0 & 0 \\
\hline GO:0006936 & muscle contraction & 339 & 2.5633 & 9.753 & 0 & 0 \\
\hline
\end{tabular}




\begin{tabular}{|l|l|r|r|r|r|r|} 
GO:0030239 & myofibril assembly & 67 & 0.5066 & 25.66 & $2.44 \mathrm{E}-15$ & $7.40 \mathrm{E}-12$ \\
\hline GO:0010927 & cellular component assembly involved in morphogenesis & 106 & 0.80149 & 17.47 & $5.62 \mathrm{E}-14$ & $1.28 \mathrm{E}-10$ \\
\hline GO:0031032 & actomyosin structure organization & 184 & 1.3913 & 11.5 & $6.27 \mathrm{E}-13$ & $1.14 \mathrm{E}-09$ \\
\hline GO:0097435 & supramolecular fiber organization & 640 & 4.8392 & 5.373 & $1.61 \mathrm{E}-12$ & $2.44 \mathrm{E}-09$ \\
\hline GO:0055001 & muscle cell development & 166 & 1.2552 & 11.95 & $1.97 \mathrm{E}-12$ & $2.56 \mathrm{E}-09$ \\
\hline GO:0030240 & skeletal muscle thin filament assembly & 14 & 0.10586 & 66.13 & $3.92 \mathrm{E}-12$ & $4.46 \mathrm{E}-09$ \\
\hline GO:0055002 & striated muscle cell development & 153 & 1.1569 & 12.1 & $9.45 \mathrm{E}-12$ & $9.54 \mathrm{E}-09$ \\
\hline GO:0014866 & skeletal myofibril assembly & 16 & 0.12098 & 57.86 & $1.29 \mathrm{E}-11$ & $1.17 \mathrm{E}-08$ \\
\hline
\end{tabular}

Although we did not detect thermal-induced sex reversal in $B$. vittatus within the $26^{\circ} \mathrm{C}-32^{\circ} \mathrm{C}$ temperature range, we examined the differentially expressed transcripts in further detail. We found that specific isoforms of JARID2 and KDM6B were over-expressed at $26^{\circ} \mathrm{C}$ (Table 3; S1 Table). Remarkably, JARID2 was the top-second gene with the highest expression difference between $26^{\circ} \mathrm{C}$ and $32^{\circ} \mathrm{C}$ (LogFoldChage $=-5.2891, F D R=8.96 \mathrm{E}-12$; Table 3). For both genes, the isoforms that were differentially expressed appeared to have retained an intron. In JARID2, the retained intron corresponds to intron 15, the third to last intron (Fig. 3), which is the same retained intron that was previously reported for $T$. scripta, A. mississippiensis, and P. vitticeps [16]. In contrast, KDM6B retained the last intron, intron 18 , instead of the second to last that was reported in the other species [16]. Careful examination of KDM6B using blastn alignments indicated, contrary to JARID2, that the isoform did not retain the full sequence of intron 18. Instead, three shorter sections of intron 18 were included in the KDM6B isoform (Fig. 3).

Fig. 3. Exon and intron structure of differentially expressed isoforms of JARID2 and KDM6B. a) Diagram of the exon/intron structure of the JARID2 isoform from $B$. vittatus that is over-expressed at $26^{\circ} \mathrm{C}$. Exons are shown as dark blue rectangles, introns are shown as light blue lines. Blastn matches to exonic sequences are shown as yellow rectangles, whereas matches to intronic sequences are indicated by pink rectangles. The green bar represents the reference genome of $A$. carolinensis. Blastn alignments were performed against this reference genome. b) Same as in a) but

Table 3. Estimated read counts for JARID2 and KDM6B (differentially expressed isoforms)

\begin{tabular}{|l|c|c|c|c|c|c|c|}
\cline { 2 - 7 } \multicolumn{2}{c|}{} & \multicolumn{2}{|c|}{ embryos at $32^{\circ} \mathrm{C}$} & \multicolumn{4}{c|}{ embryos at $26^{\circ} \mathrm{C}$} \\
\hline FoldChange & FDR & rep1 & rep2 & rep1 & rep2 & rep3 & rep4 \\
\hline
\end{tabular}




\begin{tabular}{|l|r|r|r|r|r|r|r|r|}
\hline JARID2 & -5.2891 & $8.96 \mathrm{E}-12$ & 307 & 380 & 3635 & 2143 & 8742 & 5135 \\
\hline KDM6B & -3.3684 & 0.000159 & 150 & 125 & 1305 & 933 & 5716 & 1964 \\
\hline
\end{tabular}

All embryos had hemipenes; sex has to be established through histology of gonads or genotypic analysis

277 It should be noted that $100 \%$ of the embryos presented intrusive organs (hemipenes), regardless of 278 their genotype (presence/absence of the $\mathrm{Y}$ chromosome) or whether the embryos carried testes or 279 ovaries. The presence of copulatory organs was observed from stage 35 (Fig. 4a,d). The morphology 280 in this stage corresponded to a prominent lobe that becomes slightly larger. Hemipenes became 281 bilobed in stage 36, with blood supply throughout the entire phallus (Fig. 4b,e). By stage 37, 282 hemipenes were bifurcated and bilobed with blood supply only in the apical part (Fig. 4c,f).

Fig. 4. Hemipenes are present in both male and female embryos. Females showing hemipenes in a) stage 35 , b) stage 36, c) and stage 37 . Males showing hemipenes in d) stage 35 , e) stage 36 , and f) stage 37 . Black arrows point at the hemipenes.

\section{DISCUSSION}

291 Casque-headed lizards are the only group of pleurodonts that transitioned from the ancestral XY 292 system to a more recent pair of $X Y$ chromosomes. The evolutionary forces that triggered this 293 transition have remained unclear. Here, we tested whether B. vittatus showed temperature294 dependent sex reversal and whether we could detect genetic signatures of an ancestral TSD system; 295 having a latent sex determination system could facilitate transitions between sex determination 296 systems. We contrasted genotypic data and histological data of embryos from stages 35-37 297 incubated at three different temperatures. We found no effect of incubation temperatures on the 298 development of gonads: embryos with a $Y$ chromosome developed testes, whereas embryos 299 without a Y chromosome developed ovaries. Thus, B. vittatus does not appear to show temperature300 dependent sex reversal within the $26-32^{\circ} \mathrm{C}$ temperature range. We selected these incubation 301 temperatures because they are common male-producing or female-producing temperatures in non- 
302 avian reptiles and because they represent average temperatures during the reproductive season of

303 B. vittatus [31].

305 Remarkably, we observed that JARID2 was the top-second gene with the highest expression

306 difference between low and high incubation temperatures. We found that at a lower temperature

$307\left(26^{\circ} \mathrm{C}\right)$ JARID2 retained the same intron that was previously reported for T. scripta, A. 308 mississippiensis, and $P$. vitticeps at male-producing temperatures [16]. Our results suggest that the 309 alternative splicing of JARID2 is a common trait across non-avian reptiles and appears to be a 310 reminiscence of an ancestral response to temperature [32]. We showed that the new pair of XY 311 chromosomes are dominant, however, it is still not clear whether the two XY systems co-existed or 312 whether a potentially latent TSD system facilitated the transition. Future work could explore 313 whether more extreme incubation temperatures may trigger sex reversal and the nature of the 314 signaling cascades controlled by the temperature-specific isoforms of JARID2.

316 In contrast, the differentially expressed isoform of $K D M 6 B$ did not show the expected pattern since

317 it retained shorter sections of the last intron rather than the complete sequence of the second to 318 last intron. This pattern is rather consistent with KDM6B showing alternative $3^{\prime}$-UTR and could 319 indicate that only the JARID2-dependent pathway is still sensitive to temperature changes in 320 pleurodonts.

322 Differential expression analyses showed that genes related to neuron development were over323 expressed at lower temperatures, whereas genes related to muscular development were over324 expressed at higher incubation temperatures. Embryonic development is boosted at elevated 325 incubation temperatures, however, we found that tissues responded differently to temperature. 326 Finally, our work examined for the first time to our knowledge the development of gonad during 327 stages $35-37$ in a member of the Corytophanidae family. We found that gonads were well328 differentiated and increased in size and cellular density during these stages. Intriguingly, we found 329 that all embryos showed hemipenes during stages 35-37. This result suggests heterochrony in the 330 regression of hemipenes in females (i. e., both gonad and genital structures development may not 331 be closely coordinated), as it occurs in just three phylogenetically distant lizards [33-35]. 


\section{Acknowledgements}

335 To Ana E. López-Moreno, Ailed Pérez-Pérez and Orlando Suárez-Rodríguez for aiding in the

336 collection of lizards. We also thank the community of La Selva del Marinero for field assistance.

\section{Authors' contributions}

339 G.S.-V., D.C., and O.H.-G. designed the study. G.S.-V., E.M.-C., A.A., M.V.-S.-C., and D.C. performed

340 the analyses. All authors contributed to the interpretation of the results. G.S.-V., D.C. and O.H.-G.

341 wrote the article. All authors read and approved the final article.

\section{Supporting information}

344 S1 Table: Differentially expressed genes found in this study.

\section{Data availability}

347 RNA-seq data have been deposited to the NCBI-SRA database under BioProject PRJNA766022.

\section{Ethics declarations}

350 Permission for fieldwork and sampling was granted by the Secretaría del Medioambiente y

351 Recursos Naturales (SEMARNAT Scientific Collector Permit 08-043).

\section{REFERENCES}

1. Pincheira-Donoso D, Bauer AM, Meiri S, Uetz P. Global taxonomic diversity of living reptiles. PLoS One. 2013;8(3):e59741. Epub 2013/04/02. doi: 10.1371/journal.pone.0059741. PubMed PMID: 23544091; PubMed Central PMCID: PMCPMC3609858.

360 2. Bachtrog D, Mank JE, Peichel CL, Kirkpatrick M, Otto SP, Ashman TL, et al. Sex

361 determination: why so many ways of doing it? PLoS Biol. 2014;12(7):e1001899. doi:

362 10.1371/journal.pbio.1001899. PubMed PMID: 24983465; PubMed Central PMCID:

363 PMCPMC4077654.

$3643 . \quad$ Sarre SD, Georges A, Quinn A. The ends of a continuum: genetic and temperature-

365 dependent sex determination in reptiles. Bioessays. 2004;26(6):639-45. Epub 2004/06/02. doi:

366 10.1002/bies.20050. PubMed PMID: 15170861.

367 4. Shine R, Elphick MJ, Donnellan S. Co-occurrence of multiple, supposedly incompatible 368 modes of sex determination in a lizard population. Ecology Letters. 2002;5(4):486-9.

369 5. Whiteley SL, Castelli MA, Dissanayake DSB, Holleley CE, Georges A. Temperature-Induced

370 Sex Reversal in Reptiles: Prevalence, Discovery, and Evolutionary Implications. Sex Dev. 2021;15(1-

371 3):148-56. Epub 2021/06/11. doi: 10.1159/000515687. PubMed PMID: 34111872. 
372 6. Hill PL, Burridge CP, Ezaz T, Wapstra E. Conservation of Sex-Linked Markers among

373 Conspecific Populations of a Viviparous Skink, Niveoscincus ocellatus, Exhibiting Genetic and

374 Temperature-Dependent Sex Determination. Genome Biol Evol. 2018;10(4):1079-87. doi:

375 10.1093/gbe/evy042. PubMed PMID: 29659810; PubMed Central PMCID: PMCPMC5905450.

$3767 . \quad$ Robert KA, Thompson MB. Sex determination. Viviparous lizard selects sex of embryos.

377 Nature. 2001;412(6848):698-9. doi: 10.1038/35089135. PubMed PMID: 11507628.

378 8. Cornejo-Paramo P, Dissanayake DSB, Lira-Noriega A, Martinez-Pacheco ML, Acosta A,

379 Ramirez-Suastegui C, et al. Viviparous Reptile Regarded to Have Temperature-Dependent Sex

380 Determination Has Old XY Chromosomes. Genome Biol Evol. 2020;12(6):924-30. Epub 2020/05/21.

381 doi: 10.1093/gbe/evaa104. PubMed PMID: 32433751; PubMed Central PMCID: PMCPMC7313667.

382 9. Holleley CE, O'Meally D, Sarre SD, Marshall Graves JA, Ezaz T, Matsubara K, et al. Sex

383 reversal triggers the rapid transition from genetic to temperature-dependent sex. Nature.

384 2015;523(7558):79-82. doi: 10.1038/nature14574. PubMed PMID: 26135451.

385 10. Quinn AE, Georges A, Sarre SD, Guarino F, Ezaz T, Graves JA. Temperature sex reversal

386 implies sex gene dosage in a reptile. Science. 2007;316(5823):411. doi: 10.1126/science.1135925.

387 PubMed PMID: 17446395.

388 11. Radder RS, Quinn AE, Georges A, Sarre SD, Shine R. Genetic evidence for co-occurrence of

389 chromosomal and thermal sex-determining systems in a lizard. Biol Lett. 2008;4(2):176-8. doi:

390 10.1098/rsbl.2007.0583. PubMed PMID: 18089519; PubMed Central PMCID: PMCPMC2429925.

391 12. Quinn AE, Radder RS, Sarre SD, Georges A, Ezaz T, Shine R. Isolation and development of a

392 molecular sex marker for Bassiana duperreyi, a lizard with XX/XY sex chromosomes and

393 temperature-induced sex reversal. Mol Genet Genomics. 2009;281(6):665-72. Epub 2009/03/12.

394 doi: 10.1007/s00438-009-0437-7. PubMed PMID: 19277717.

395 13. Pennell MW, Mank JE, Peichel CL. Transitions in sex determination and sex chromosomes

396 across vertebrate species. Mol Ecol. 2018. doi: 10.1111/mec.14540. PubMed PMID: 29451715.

397 14. Gamble T, Coryell J, Ezaz T, Lynch J, Scantlebury DP, Zarkower D. Restriction Site-

398 Associated DNA Sequencing (RAD-seq) Reveals an Extraordinary Number of Transitions among

399 Gecko Sex-Determining Systems. Mol Biol Evol. 2015;32(5):1296-309. doi:

400 10.1093/molbev/msv023. PubMed PMID: 25657328.

401 15. Sabath N, Itescu Y, Feldman A, Meiri S, Mayrose I, Valenzuela N. Sex determination,

402 longevity, and the birth and death of reptilian species. Ecol Evol. 2016;6(15):5207-20. doi:

403 10.1002/ece3.2277. PubMed PMID: 27551377; PubMed Central PMCID: PMCPMC4984498.

404 16. Deveson IW, Holleley CE, Blackburn J, Marshall Graves JA, Mattick JS, Waters PD, et al.

405 Differential intron retention in Jumonji chromatin modifier genes is implicated in reptile

406 temperature-dependent sex determination. Sci Adv. 2017;3(6):e1700731. doi:

407 10.1126/sciadv.1700731. PubMed PMID: 28630932; PubMed Central PMCID: PMCPMC5470834.

408 17. Georges A, Ezaz T, Quinn AE, Sarre SD. Are reptiles predisposed to temperature-dependent

409 sex determination? Sex Dev. 2010;4(1-2):7-15. doi: 10.1159/000279441. PubMed PMID:

41020110654.

411 18. Dissanayake DSB, Holleley CE, Deakin JE, Georges A. High elevation increases the risk of Y

412 chromosome loss in Alpine skink populations with sex reversal. Heredity (Edinb). 2021;126(5):805-

413 16. Epub 2021/02/03. doi: 10.1038/s41437-021-00406-z. PubMed PMID: 33526811; PubMed

414 Central PMCID: PMCPMC8102603.

415 19. Ge C, Ye J, Weber C, Sun W, Zhang H, Zhou Y, et al. The histone demethylase KDM6B

416 regulates temperature-dependent sex determination in a turtle species. Science.

417 2018;360(6389):645-8. Epub 2018/05/12. doi: 10.1126/science.aap8328. PubMed PMID:

41829748283. 
419

20. Czerwinski M, Natarajan A, Barske L, Looger LL, Capel B. A timecourse analysis of systemic and gonadal effects of temperature on sexual development of the red-eared slider turtle Trachemys scripta elegans. Dev Biol. 2016;420(1):166-77. Epub 2016/09/28. doi: 10.1016/j.ydbio.2016.09.018. PubMed PMID: 27671871.

21. Altmanova M, Rovatsos M, Johnson Pokorna M, Vesely M, Wagner F, Kratochvil L. All iguana families with the exception of basilisks share sex chromosomes. Zoology (Jena). 2018;126:98-102. doi: 10.1016/j.zool.2017.11.007. PubMed PMID: 29287619.

22. Rovatsos M, Pokorna M, Altmanova M, Kratochvil L. Cretaceous park of sex determination: sex chromosomes are conserved across iguanas. Biol Lett. 2014;10(3):20131093. doi: 10.1098/rsbl.2013.1093. PubMed PMID: 24598109; PubMed Central PMCID: PMCPMC3982436. 23. Marin R, Cortez D, Lamanna F, Pradeepa MM, Leushkin E, Julien P, et al. Convergent origination of a Drosophila-like dosage compensation mechanism in a reptile lineage. Genome Res. 2017;27(12):1974-87. doi: 10.1101/gr.223727.117. PubMed PMID: 29133310; PubMed Central PMCID: PMCPMC5741051.

24. Acosta A, Suarez-Varon G, Rodriguez-Miranda LA, Lira-Noriega A, Aguilar-Gomez D, Gutierrez-Mariscal M, et al. Corytophanids Replaced the Pleurodont XY System with a New Pair of XY Chromosomes. Genome Biol Evol. 2019;11(9):2666-77. Epub 2019/09/27. doi: 10.1093/gbe/evz196. PubMed PMID: 31557287.

25. Nielsen SV, Guzman-Mendez IA, Gamble T, Blumer M, Pinto BJ, Kratochvil L, et al. Escaping the evolutionary trap? Sex chromosome turnover in basilisks and related lizards (Corytophanidae: Squamata). Biol Lett. 2019;15(10):20190498. Epub 2019/10/09. doi: 10.1098/rsbl.2019.0498. PubMed PMID: 31594492; PubMed Central PMCID: PMCPMC6832183.

26. Dufaure JP, Hubert J. Table de développement du lézard vivipare: Lacerta (Zootoca) vivipara jacquin. Arch Anat Microsc Morphol Exp. 1961;50:309-28.

27. Grabherr MG, Haas BJ, Yassour M, Levin JZ, Thompson DA, Amit I, et al. Full-length transcriptome assembly from RNA-Seq data without a reference genome. Nat Biotechnol. 2011;29(7):644-52. doi: 10.1038/nbt.1883. PubMed PMID: 21572440; PubMed Central PMCID: PMCPMC3571712.

28. Bray NL, Pimentel H, Melsted P, Pachter L. Near-optimal probabilistic RNA-seq quantification. Nat Biotechnol. 2016;34(5):525-7. doi: 10.1038/nbt.3519. PubMed PMID: 27043002.

29. Robinson MD, McCarthy DJ, Smyth GK. edgeR: a Bioconductor package for differential expression analysis of digital gene expression data. Bioinformatics. 2010;26(1):139-40. Epub 2009/11/17. doi: 10.1093/bioinformatics/btp616. PubMed PMID: 19910308; PubMed Central PMCID: PMCPMC2796818.

30. Altschul SF, Gish W, Miller W, Myers EW, Lipman DJ. Basic local alignment search tool. Journal of molecular biology. 1990;215(3):403-10. doi: 10.1016/50022-2836(05)80360-2. PubMed PMID: 2231712.

31. Cornejo-Paramo P, Lira-Noriega A, Ramirez-Suastegui C, Mendez-de-la-Cruz FR, Szekely T, Urrutia AO, et al. Sex determination systems in reptiles are related to ambient temperature but not to the level of climatic fluctuation. BMC Evol Biol. 2020;20(1):103. Epub 2020/08/19. doi: 10.1186/s12862-020-01671-y. PubMed PMID: 32807071; PubMed Central PMCID: PMCPMC7433102.

32. Haltenhof T, Kotte A, De Bortoli F, Schiefer S, Meinke S, Emmerichs AK, et al. A Conserved Kinase-Based Body-Temperature Sensor Globally Controls Alternative Splicing and Gene Expression. Mol Cell. 2020;78(1):57-69 e4. Epub 2020/02/16. doi: 10.1016/j.molcel.2020.01.028. PubMed PMID: 32059760. 
466 33. Martinez-Torres M, Rubio-Morales B, Pina-Amado JJ, Luis J. Hemipenes in females of the Mexican viviparous lizard Barisia imbricata (Squamata: Anguidae): an example of heterochrony in sexual development. Evol Dev. 2015;17(5):270-7. Epub 2015/09/16. doi: 10.1111/ede.12134.

469 PubMed PMID: 26372061.

470 34. Neaves L, Wapstra E, Birch D, Girling JE, Joss JM. Embryonic gonadal and sexual organ 471 development in a small viviparous skink, Niveoscincus ocellatus. J Exp Zool A Comp Exp Biol. 472 2006;305(1):74-82. Epub 2005/12/17. doi: 10.1002/jez.a.249. PubMed PMID: 16358273.

473 35. Whiteley SL, Weisbecker V, Georges A, Gauthier ARG, Whitehead DL, Holleley CE.

474 Developmental asynchrony and antagonism of sex determination pathways in a lizard with 475 temperature-induced sex reversal. Sci Rep. 2018;8(1):14892. Epub 2018/10/07. doi:

476 10.1038/s41598-018-33170-y. PubMed PMID: 30291276; PubMed Central PMCID:

477 PMCPMC6173690. 


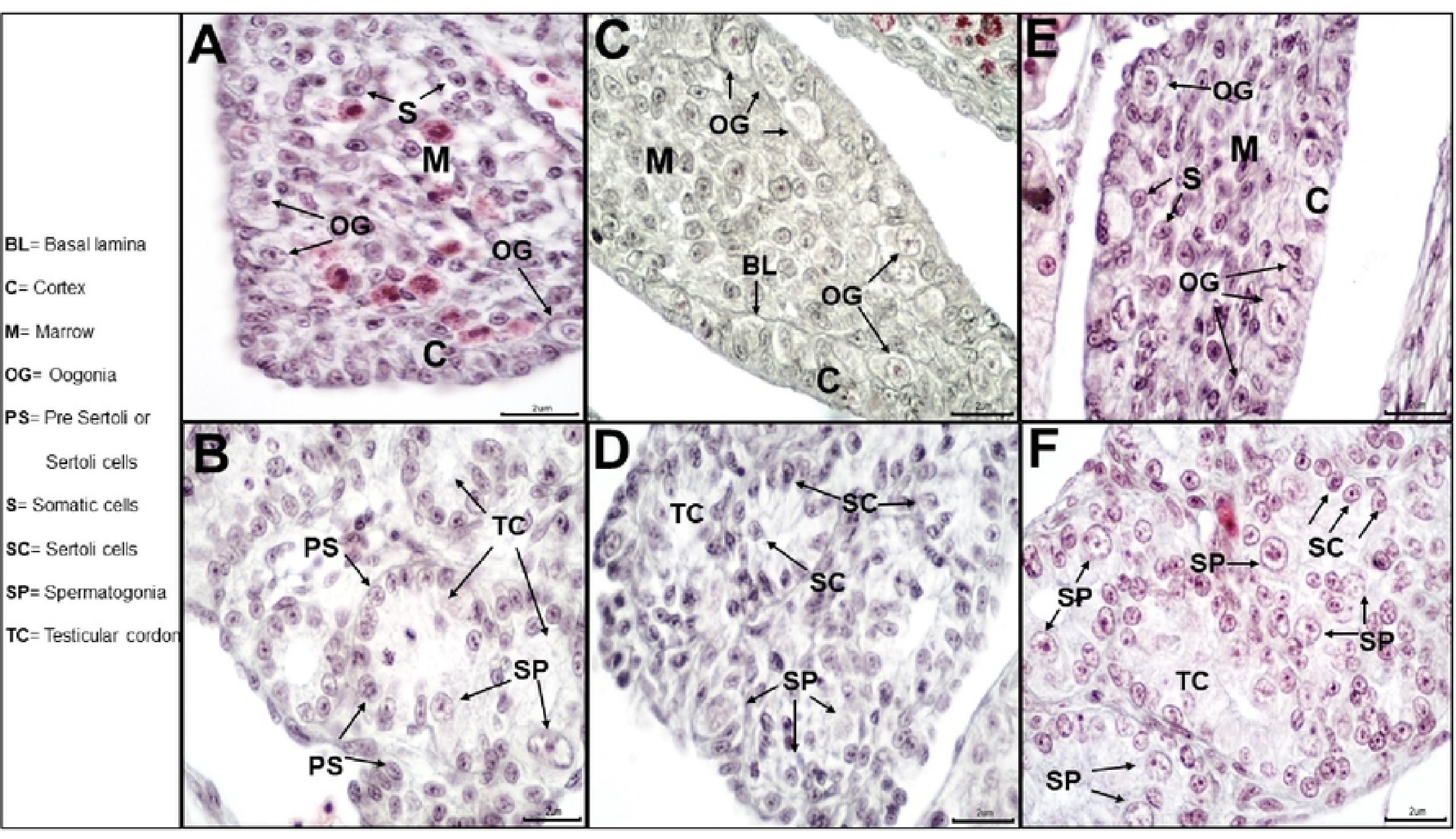

Figure1 


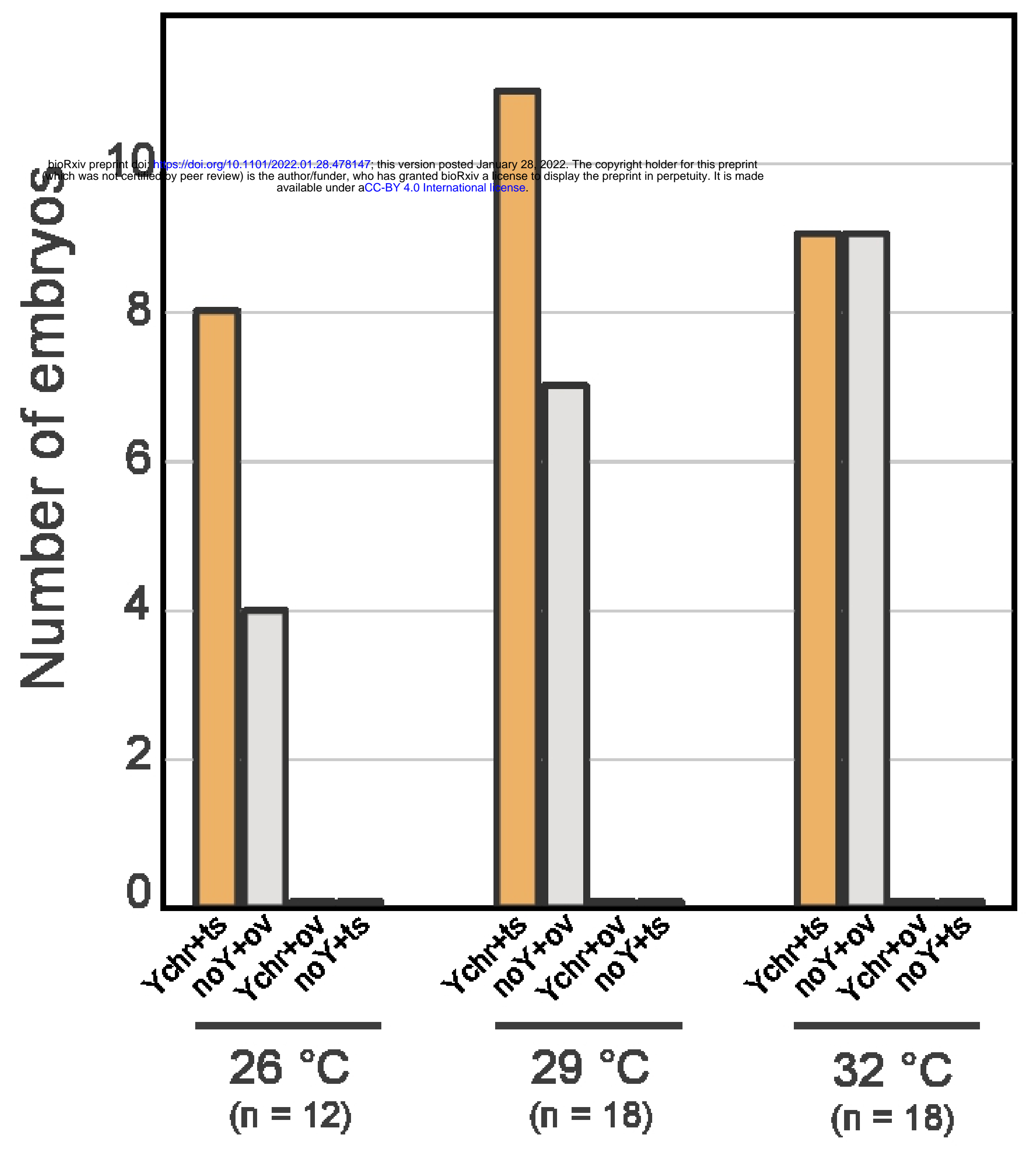

Figure2 
a)

JARID2-201, 18 exons, on chromosome 4 (A. corolinensis)

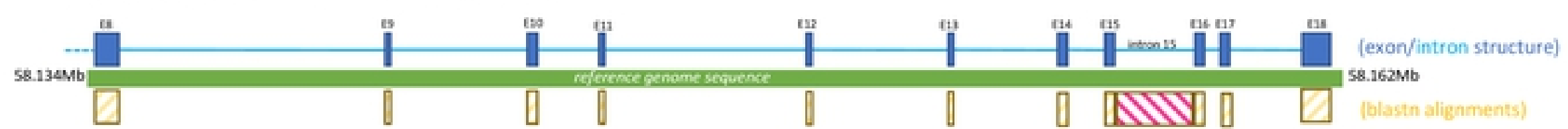

b)

KDM6B-201, 18 exons, on GL343784.1 (A. corolinensis)

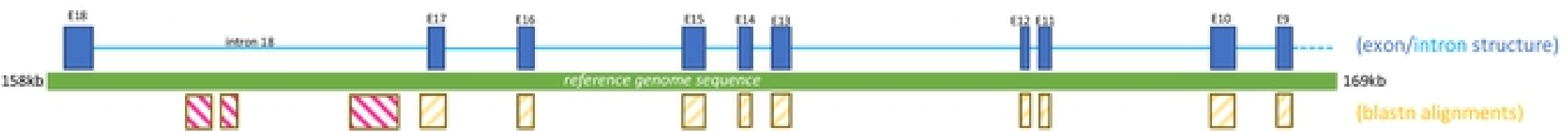

Figure3 


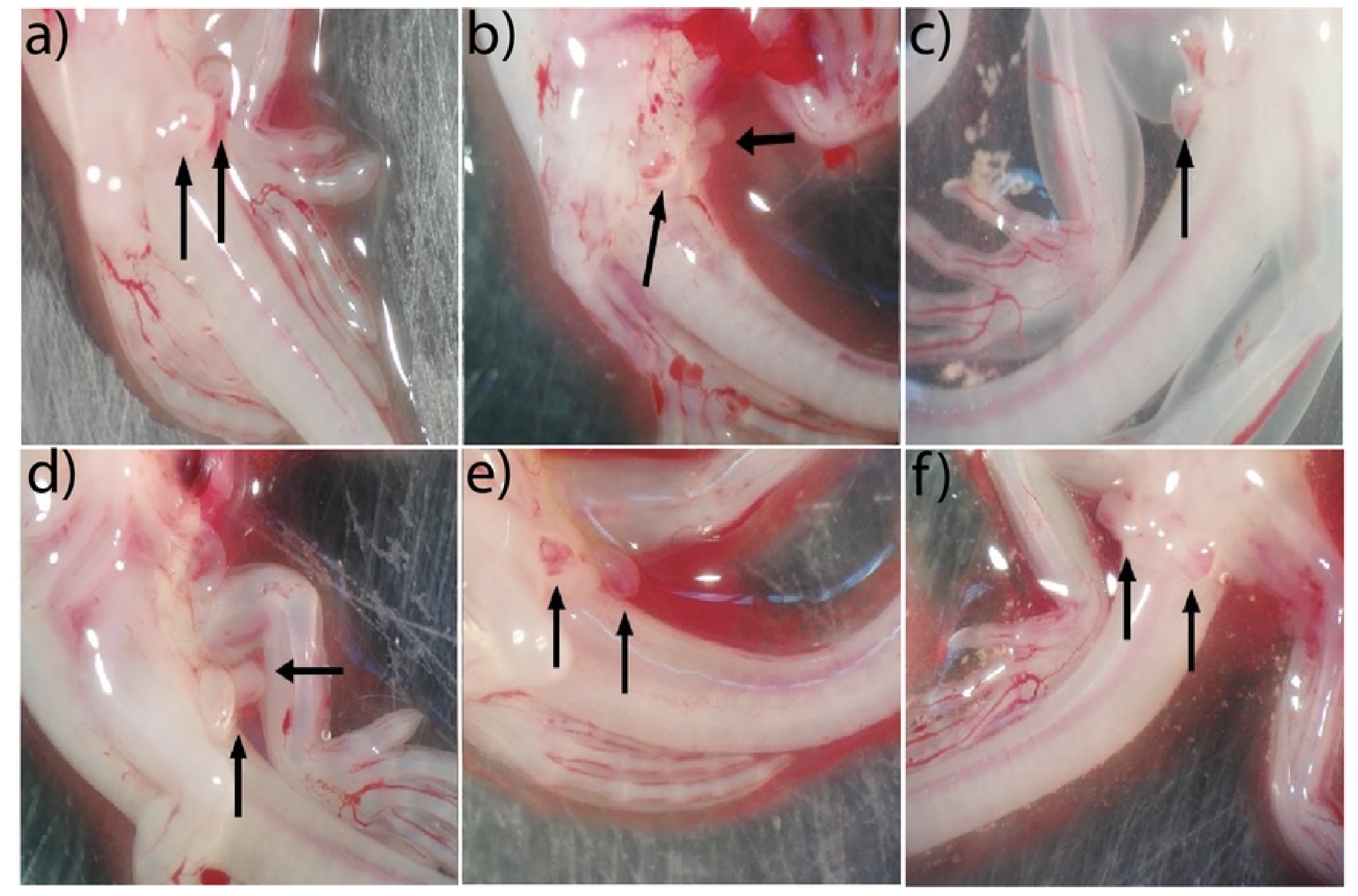

Figure4 